\title{
THE CORRELATION BETWEEN SEXUAL BEHAVIORS AND SEXUAL TRANSMITTED DISEASES IN MEN
}

\author{
Nguyen Hoai Bac ${ }^{1, \bowtie}$, Hoang Long ${ }^{2}$ \\ ${ }^{1}$ Hanoi Medical University, \\ ${ }^{2}$ Hanoi Medical University Hospital
}

Sexually transmitted diseases (STDs) have been a public health issue in many developing countries, especially in Vietnam. Unsafe sex is considered to be one of the main causes to increase infected person. Therefore, we conducted a study on 3005 men who presented to the Andrology and Sexual Medicine Units of Hanoi Medical University Hospital to analyze the correlation between sexual behaviors and sexually transmitted diseases in men. The result showed that the mean age at first sex (AFS) was 21 years old. The median number of stable sexual partners was 2, the overall rate of STDs was $9.95 \%$, in particular, the proportion of STDs in single men was higher than the married group (11.8\% and $7.5 \%, p<0.001)$, men having first intercourse before 25 years old had the rate of STDs was higher compared with their counterpart (21.1\% vs. $13.2 \%, p=0.002)$. Subjects with multiple unstable sexual partners were 2.11 times more likely to be infected with STDs, and the risk of infecting STDs would rise $6 \%$ for each additional sex partner.

Keywords: Men, risk, STDs, sexual behaviors.

\section{INTRODUCTION}

Nowadays, sexually transmitted diseases (STDs) is a major public health issue over the world, ${ }^{1}$ especially in developing countries such as Vietnam. According to the World Health Organization, more than 1 million people around the globe contract a sexually transmitted disease every day. ${ }^{2}$ That's approximately 357 million new infections each year, it can lead to serious consequences on general health as well as reproductive health in both men and women. There are many sexual behaviors that increase the spread of STDs including unsafe sex, multiple sexual partners, and substance abuse. ${ }^{3}$ A study was conducted among Chinese clients, the prevalence of STDs was $51 \%$ ( $70 \%$ of men and $35 \%$ of women), who had STDs diagnosed

Corresponding author: Nguyen Hoai Bac,

Ha Noi Medical University

Email: Nguyenhoaibac@hmu.edu.vn

Received: 19/02/2021

Accepted: 08/04/2021 were more likely to be male, never married, have had casual sex or multiple sexual partners $(63 \%) .{ }^{4}$ In Vietnam, the economic development and the integration of social - cultural has made young people more and more open to sexual related matters. According to statistic from Dermatology unit across the country, there were 200.000 new cases of STD each year, but the incidence of STD was likely to be much higher due to asymptomatic or mild cases. The prevalence of STDs in Vietnam has reached $17.3 \%$ in 2017 . However, sexual education has not been appreciated. Lack of knowledge about sexual safety and unhealthy sexual habits have negative effects on Vietnamese juveniles and adults through increasing sexually transmitted diseases. ${ }^{5}$ Furthermore, the data of STDs on the male population was lacking. Therefore, we conducted this study to describe the common sexual behaviors of men and identify the relationship between men's sexual behaviors to the risk of infecting STDs. 


\section{METHODS}

\section{Subjects}

Patients who presented to the Andrology and Sexual Medicine Units of Hanoi Medical University Hospital from January 2020 to September 2020.

Inclusion criteria:

- Men between 16 and 60 years old.

- Have at least 1 sexual intercourse.

- Have adequate information of sexual habits and medical history of sexually transmitted diseases.

\section{Exclusion criteria:}

- Patients refused to participate in the study or agreed to the informed consent.

- Patients under 18 years old without the approval of their guardians.

All potential responders were clearly advised that participation in this survey was voluntary and anonymous.

\section{Methods}

Study design: A cross - sectional study

\section{Study procedure:}

Patients who were examined at the Andrology and Sexual Medicine Units of Hanoi Medical University Hospital were interviewed face to face to obtain complete information about administration, occupation, medical history, and sexual behaviors.

The factors of sexual behaviors included: number of stable sexual partners, age at first sex, age of marriage, status with one - time partners, masturbation during the last 3 months.

Diagnosis of sexually transmitted diseases was based on: epidemiology of the patients having sexual intercourse before the onset of symptoms, having clinical symptoms of genitourinary tract infection, with or without urethral discharge, not found pathogenic bacteria through urethral microscopy, a culture of the specimen (urethral discharge culture) or more advanced tests (such as PCR tests) or prostate fluid was positive with the pathogen.

Some concepts used in this research:

Stable sexual partners are partners who have regular relationships for a long time (more than 3 months): These partners are usually wife, lovers...

"One - time" partners are those who have a short period of time. These partners are usually sex workers, acquaintances, business partners, ex - girlfriends...

Stimulants are substances commonly used before sexual intercourse such as alcohol, beer, cannabis, drugs....

\section{Statistical analysis}

Software $\mathrm{R}$ version 4.0.2 for Windows 10 operating system was used to process data in this study. Standard normal distribution was evaluated by the Kolmogorov - Smirnov test The difference between two groups was tested by Wilcoxon test with non - standard distribution quantitative variables and Chi squared test with qualitative variables. Logistic regression models were used to predict the probability of STDs in patients with multiple sexual partners and 'one - time' partners. The result was considered statistically significant with $p$ value $<0.05$.

\section{Ethical considerations}

The study was approved by the Board of Directors of Hanoi Medical University hospital. All information and comments were encoded without revealing personal information.

\section{RESULTS}

This study was conducted on 3005 patients who presented to the Andrology and Sexual Medicine Units, we obtained the following results: The median age of first sex was 21 years old. Mean number of sexual partners was 2. The prevalence of STDs accounted for $9.95 \%$. 


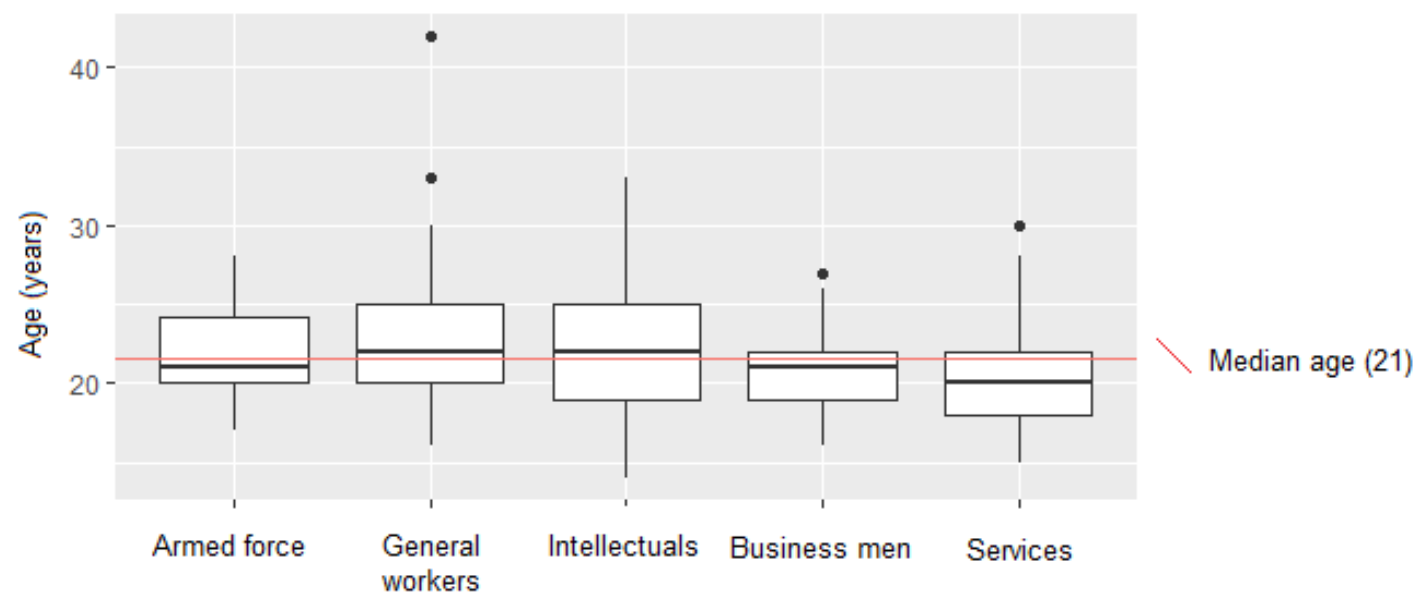

\section{Figure 1. Age of first sexual inercourse}

Participants in service field had the earliest age at first sex with median was 20 , in contrast to the intellectuals and general workers with the latest age of first sex was 22 years old.

Table 1. General characteristics of participants

\begin{tabular}{|c|c|c|c|c|c|}
\hline & \multicolumn{2}{|c|}{ Without STDs } & \multicolumn{2}{|c|}{ STDs } & \multirow[t]{2}{*}{$\mathbf{p}$} \\
\hline & $\mathrm{n}$ & $\%$ & $\mathrm{n}$ & $\%$ & \\
\hline Year of birth & & & & & 0.074 \\
\hline$<1990$ & 1411 & 51.6 & 125 & 46 & \\
\hline$\geq 1990$ & 1322 & 48.4 & 147 & 54 & \\
\hline Smoking & & & & & 0.115 \\
\hline Yes & 2077 & 76 & 195 & 71.7 & \\
\hline No & 656 & 24 & 77 & 28.3 & \\
\hline Using stimulants & & & & & $<0.001$ \\
\hline Yes & 85 & 3.1 & 19 & 7 & \\
\hline No & 656 & 96.9 & 253 & 93 & \\
\hline Marriage status & & & & & $<0.001$ \\
\hline Single & 995 & 88.2 & 134 & 11.8 & \\
\hline Married & 1711 & 92.5 & 138 & 7.5 & \\
\hline Disvorded & 19 & 100 & 0 & 0 & \\
\hline Occupations & & & & & 0.174 \\
\hline Armed Forces & 106 & 3.9 & 14 & 5.1 & \\
\hline
\end{tabular}




\begin{tabular}{lccccc}
\hline & Without STDs & \multicolumn{2}{c}{ STDs } & p \\
\hline & $\mathrm{n}$ & $\%$ & $\mathrm{n}$ & $\%$ \\
\hline General workers & 631 & 23.2 & 58 & 21.3 \\
\hline Intellectuals & 1125 & 41.3 & 97 & 35.7 \\
\hline Business men & 431 & 15.8 & 53 & 19.5 \\
\hline Services & 430 & 15.8 & 50 & 18.4 \\
\hline
\end{tabular}

The subjects were born after 1990 had a higher rate of STDs than the other group (54\% and 46\% with $p>0.005)$. Similarly, single men had a higher rate of STDs than married men $(11.8 \%$ and $7.5 \%$ with $\mathrm{p}<0.001)$. In addition, people using stimulants also reported higher proportion of STDs than the other group ( $7 \%$ and $3.1 \%$ with $p<0.001)$.

Table 2. Sexual characteristics of participations $(n=3005)$

\begin{tabular}{|c|c|c|c|c|c|c|c|c|c|}
\hline \multirow[t]{2}{*}{ Characteristics } & \multicolumn{4}{|c|}{ Without STDs } & \multicolumn{4}{|c|}{ STDs } & \multirow[t]{2}{*}{$\mathbf{p}$} \\
\hline & $\mathbf{N}$ & $\%$ & $\begin{array}{l}\text { Mean } \\
\text { (SD) }\end{array}$ & $\begin{array}{l}\text { Median } \\
\text { (min - } \\
\text { max) }\end{array}$ & $\mathbf{N}$ & $\%$ & $\begin{array}{l}\text { Mean } \\
\text { (SD) }\end{array}$ & $\begin{array}{l}\text { Median } \\
\text { (min - } \\
\text { max) }\end{array}$ & \\
\hline $\begin{array}{l}\text { Age at first sex } \\
\text { (year) }\end{array}$ & & & & & & & & & 0.002 \\
\hline$<25$ & 2157 & 78.9 & & & 236 & 21.1 & & & \\
\hline$>=25$ & 576 & 86.7 & & & 36 & 13.2 & & & \\
\hline $\begin{array}{l}\text { Age of marriage } \\
\text { (year) }\end{array}$ & & & $\begin{array}{l}25.26 \\
(7.26)\end{array}$ & $\begin{array}{c}26 \\
(20-47)\end{array}$ & & & $\begin{array}{l}24.07 \\
(8.66)\end{array}$ & $\begin{array}{c}26 \\
(0-39)\end{array}$ & 0.056 \\
\hline $\begin{array}{l}\text { Number of stable } \\
\text { sexual partners } \\
\text { (person) }\end{array}$ & v & & $\begin{array}{c}2.84 \\
(2.76)\end{array}$ & $\begin{array}{c}2 \\
(0-40)\end{array}$ & & & $\begin{array}{c}3.67 \\
(3.39)\end{array}$ & $\begin{array}{c}3 \\
(0-32)\end{array}$ & $<0.001$ \\
\hline Masturbation & & & & & & & & & 0.069 \\
\hline Yes & 475 & 17.7 & & & 35 & 13.3 & & & \\
\hline No & 2209 & 82.3 & & & 229 & 86.7 & & & \\
\hline $\begin{array}{l}\text { "One - time" } \\
\text { sexual partners }\end{array}$ & & & $f$ & & & & & & $<0.001$ \\
\hline No & 1618 & 59.2 & & & 114 & 41.9 & & & \\
\hline Yes & 1115 & 40.8 & & & 158 & 58.1 & & & \\
\hline
\end{tabular}

Patients with STDs had more stable sexual partners than those without STDs. Patients who had sex with "one - time" partners had a higher proportion of STDs than the other group. 
Table 3. Factors influence the risk of infecting STDs

\begin{tabular}{|c|c|c|c|c|}
\hline Factors & $\mathbf{N}$ & OR & $95 \% \mathrm{Cl}$ & $\mathbf{p}$ \\
\hline \multicolumn{5}{|l|}{ Age of birth } \\
\hline$<1990$ & 1536 & 1 & & \\
\hline$\geq 1990$ & 1469 & 0.93 & $0.53-1.56$ & 0.7 \\
\hline \multicolumn{5}{|l|}{ Age at first sex (year) } \\
\hline$<25$ & 2393 & 1 & & \\
\hline$\geq 25$ & 612 & 0.8 & $0.46-1.49$ & 0.58 \\
\hline \multicolumn{5}{|l|}{ Masturbation } \\
\hline Yes & 510 & 0.86 & $0.52-1.46$ & 0.57 \\
\hline No & 2438 & 1 & & \\
\hline \multicolumn{5}{|l|}{ "One - time" sexual partners } \\
\hline Yes & 1273 & 2.11 & $1.3-3.46$ & 0.002 \\
\hline No & 1732 & 1 & & \\
\hline \multicolumn{5}{|c|}{ Number of sexual partners (person) } \\
\hline \multirow[t]{2}{*}{1} & 1377 & 1 & & \\
\hline & & & & $<$ \\
\hline$>1$ & 1628 & 1.06 & $1.03-1.1$ & 0.001 \\
\hline
\end{tabular}

The multiple logistic regression showed that having sex with 'one - time' sexual partners and multiple sexual partners increased the risks of STDs. Patients with 'one - time' sexual partner were 2.11 times more likely to be infected with STDs with $p=0.002$ and the risk of infecting STDs was $6 \%$ higher for each additional sex partners.

\section{DISCUSSION}

In this study, men had the median age of first sex of 21 (Figure 1), lower than the age of marriage according to the GSO statistics which was $25.2 .^{6}$ This make the change of sexual behaviors, unlike with previous traditional beliefs. There were many factors that influence pre - marital sexual behaviors especially in cultural integration, information from the internet and smartphones. However, the age at first sex in our research was higher than in other studies such as the US (17.1 years old $)^{7}$, European $(15.4)^{8}$ and China (18.6). ${ }^{9}$ This can be partly explained based on the formation of the Vietnamese beliefs following the Asian ideology until present day, sex before marriage remained a stigma to the society. Studies showed that the age at first sex was lower than marriage age may increases the number of sexual partners ${ }^{7}$ and becoming a potential cause to get sexually transmitted diseases.

Also in this study, young single men had a high prevalence of STDs (11.8\%) (Table $1)$. This can be explained that they have not yet committed to marriage or social ethics, therefore they can freely change their partners and more open - minded towards sexuality issues $^{10}$. In addition, young men were more likely to access information on the internet which included a substantial amount of sexual contents. Besides, men believed that having 
more than one sexual partner was their symbol of masculinity. In contrast, the percentage of STDs in married group was much lower $(7.5 \%$ with $p<0.001$ ) (Table 1).

The stimulants such as alcohol, beer, cannabis, or other drugs can be one of the reasons to the increased risk of STDs. The results also showed that the proportion of using stimulants with STDs was 7\%, twice than that of those who did not use stimulants with STDs (3.1\%, $p<0.001$ - Table 1). This results implied a relation between stimulants and STDs because of the inability to control their behaviors which led to impulsive sexual activity, mostly unsafe. ${ }^{11}$

Many studies reported that the first sexual activity at a young age and multiple sexual partners were likely greatly increases the probability of becoming infected with STDs in men. ${ }^{12,} 13$ In this study, the proportion of patients with STDs was higher among those who began sexual activity under the age of 25 (21.1\% vs $13.2 \% p=0.002$ ) (Table 2). Patients who had sex with a 'one - time' partner had a higher prevalence of STDs than other $(58.1 \%$ vs $41.9 \%$ ). In addition, we also found that the number of sexual partners in patients with STDs was 3 partners, higher than the group without STDs (Table 2).

The multiple logistic regression showed that having sex with "one time" and more than one partner were contributed to an increased risk of STDs. Patients with "one - time" sexual partners were 2.11 times more likely to be infected with STDs and the risk of infecting STDs was $6 \%$ higher for each additional sexual partner (Table 3 ). This result indicated a need of sex education for adolescents as well as young adults about the hazard of multiple sexual partners.

Our study had a few limitations. Firstly, the study was conducted on patients who examined at Hanoi Medical University hospital so the results may not reflect accurately in the community. Secondly, some information related to sexual behaviors was taken by interviewing patients directly. Therefore, recall errors may affect the results of study.

\section{CONCLUSION}

The prevalence of STDs in men who attended the Andrology Unit at Hanoi University Hospital was $9.95 \%$. The risk of STDs was higher in single men and beginning sexual activity at a young age. Having sex with one - night stand sexual partners were 2.11 times more likely to be infected with STDs and the risk of infecting STDs would rise $6 \%$ for each additional sexual partner.

\section{Acknowledgments}

We would like to express my heartiest thanks to supporters and health care providers in Andrology and Sexual Medicine Units of Hanoi Medical University Hospital for their great support during the time of collecting data. Many thanks go in particular to patients for their willing help to answer the questionnaire.

\section{REFERENCES}

1. Fonck K KN, Kirui $P$, et al. Pattern of sexually transmitted diseases and risk factors among women attending an STD referral clinic in Nairobi, Kenya. Sex Transm Dis. 2000;27:417 $-423$.

2. WHO warns of 1 million new sexually transmitted diseases each day. World Health Organization (WHO). 2019;

3. Report on global sexual transmitted infection surveillance. World Health Organization (2018).

4. Abu S. M. Abdullah M, Mph, Phd, Richard Fielding, Phd, Anthony J. Hedley, Md, Ffphm, And Yee K. Luk, Mstat. Risk Factors for Sexually Transmitted Diseases and Casual Sex 
Among Chinese Patients Attending Sexually Transmitted Disease Clinics in Hong Kong. Department of Community Medicine, The University of Hong Kong, Hong Kong, China. 2001;

5. Nguyễn Thị Thanh Phương, Nguyễn Hữu Đức Anh, et al. Knowledge and attitudes about sexually transmitted diseases among university students in Hanoi in 2019. Journal of Medical Research 2020;(2):129 - 137.

6. Results from entire population and housing census in 2019. General Statistics Office 2019.

7. Ku L. SFL, and Pleck J. H. Factors Influencing First Intercourse for Teenage Men. . Public Health Rep. 1993;15(108):680 - 694.

8. A. K. ZGAB. Early sexual initiation in Europe and its relationship with legislative change: A systematic review. International Journal of Law, Crime and Justice. 2019;(57):70 $-82$.

9. Lê Minh Vũ. Pre - marital sex: a study comparing young people in Hanoi, Shanghai, and Taiwan. ournal of Experimental Sociology. 2010;(2):21 - 30.

10. C KSaL. Factors Affecting Sexually Transmitted Infections in South Korean High School Students. Public Health Nurs. 2016;33(3):179 - 188.

11. Brookmeyer K. A. HLT, Hogben M et al. Sexual risk behaviors and STDs among persons who inject drugs: A national study. Preventive Medicine, . 2019;(126):105779.

12. Hansen B. T. KSK, Arnheim - Dahlström $L$ et al. Age at first intercourse, number of partners and sexually transmitted infection prevalence among Danish, Norwegian and Swedish women: estimates and trends from nationally representative cross - sectional surveys of more than 100000 women. Acta Obstet Gynecol Scand. 2020;99(2):175 - 185.

13. C. E K. Young Age at First Sexual Intercourse and Sexually Transmitted Infections in Adolescents and Young Adults. American Journal of Epidemiology. 2005;161(774 - 780) 